Article

\title{
Spatio-Temporal Assessment of Climate Change Impact on Wave Energy Resources Using Various Time Dependent Criteria
}

\author{
Bahareh Kamranzad ${ }^{1,2, *(1)}$, George Lavidas ${ }^{3}$ (D) and Kaoru Takara ${ }^{2}$ \\ 1 The Hakubi Center for Advanced Research, Kyoto University, Kyoto 606-8501, Japan \\ 2 Graduate School of Advanced Integrated Studies in Human Survivability (GSAIS), Kyoto University, \\ Kyoto 606-8306, Japan; takara.kaoru.7v@kyoto-u.ac.jp \\ 3 Faculty of Maritime, Mechanical \& Materials Engineering, Delft University of Technology, 2600 AA Delft, \\ The Netherlands; G.Lavidas@tudelft.nl \\ * Correspondence: kamranzad.bahareh.3m@kyoto-u.ac.jp or bahareh.kamranzad@gmail.com
}

Received: 9 January 2020; Accepted: 5 February 2020; Published: 10 February 2020

\begin{abstract}
The wave energy resources in the Indian Ocean can be considered as a potential alternative to fossil fuels. However, the wave energy resources are subject to short-term fluctuations and long-term changes due to climate change. Hence, considering sustainable development goals, it is necessary to assess both short-term (intra-annual) variation and long-term change. For this purpose, the simulated wave characteristics were utilized, and the wave power and its variation and change were analyzed in the whole domain and nearshore areas. The short-term fluctuation was investigated in terms of monthly and seasonal variations and the future change was discussed based on absolute and relative changes. Both analyses show that the Southern Indian Ocean, despite experiencing extreme events and having higher wave energy potential, is more stable in terms of both short and long-term variation and change. The assessment of the total and exploitable storages of wave energy and their future change revealed the higher potential and higher stability of the nearshores of the Southern Indian Ocean. It can be concluded that based on various factors, the south of Sri Lanka, Horn of Africa, southeast Africa, south of Madagascar and Reunion and Mauritius islands are the most suitable areas for wave energy extraction.
\end{abstract}

Keywords: wave energy; wave power; monthly variability; climate stability; Indian Ocean

\section{Introduction}

The Indian Ocean as a region encompasses a considerable population of the earth, which live in surrounding lands. Such a population belongs to various countries in Asia, Africa and Australia with different future perspectives, development plans and priorities. However, one of the fundamental issues for all of those nations is access to the supply of energy. As well as the continental coasts, islands such as Maldives, Sri Lanka, Madagascar, Reunion, Mauritius, etc. in the Indian Ocean are the home to a large population and destination to various activities. Hence, providing the energy demand is of great importance and somehow challenging, especially considering the high number of inhabiting populations.

Since not all of the countries in the Indian Ocean region own their fossil fuels, and taking into account the disadvantages of such resources especially in their global warming contribution, finding alternatives to supply the energy is vital. Considering the global tendency to the usage of renewable energies and especially the ocean resources in the areas adjacent to water bodies, the Indian Ocean can be considered as a potential source of energy for the population living in surrounding areas. The previous studies have shown that parts of the Indian Ocean wave climate are swell dominated (e.g., [1]), 
which considering the advantages of utilizing the wave energy, such as predictability, higher density and lower visual and environmental impacts [2], provides a more stable supply of energy. However, due mainly to the lack of vast information about the climate regime, the Indian Ocean has been less studied for that purpose.

The previous studies on wave energy resources assessment in the Indian Ocean have mostly focused on regional scales, and most of them have been performed in the Northern Indian Ocean by India (covering the Arabian Sea and the Bay of Bengal) and Iran (covering including the Persian Gulf and the Gulf of Oman), as well as other studies on the Red Sea. In India a 10-yearly simulated wave dataset has been used to estimate the wave energy potential in nearshore areas [3]. Aboobacker [4] also assessed the wave energy potential in the eastern Bay of Bengal and Malacca Strait and showed that the wave power is affected by the southwest monsoon and the swells propagate from the Southern Indian Ocean. In the Persian Gulf, Etemad-Shahidi et al. [5] assessed the available wave energy based on the modeled wave dataset using localized ERA-40 wind dataset [6], while later, Kamranzad et al. [7] investigated the short-term variation in wave energy resources in terms of monthly and seasonal variations. Then, Kamranzad et al. [8] assessed the impact of climate change on wave energy there using scenarios obtained from the Coupled Model Intercomparison Project (CMIP) Phase 3, to evaluate the long-term changes, as well, and after that, they developed the Optimum Hotspot Identifier (OHI) in order to specify the most appropriate location in the Persian Gulf for wave energy extraction based on the amount of energy, frequency of extractable energy and stability of energy [9]. In addition, based on the stability of the wind and wave climate in intra-annual scales, Kamranzad [10] suggested a zone classification for the Persian Gulf. Recently, Mahmoodi et al. [11] used ERA-5 reanalysis dataset to re-estimate the wave energy resources in the Persian Gulf. In addition, Langodan et al. [12] used an 18-yearly simulated wave dataset to investigate the wind and wave energy potential in the Red Sea. They concluded that there was no potential site for wave energy extraction considering its potential and the efficiency and available converters. Later, Aboobacker et al. [13] used 32-yearly simulated wave dataset to assess the inter- and intra-annual variability of wave power in the Red Sea and showed that the highest mean annual wave power reaches around $4.5 \mathrm{~kW} / \mathrm{m}$, while in nearshore areas in does not exceed $2 \mathrm{~kW} / \mathrm{m}$.

Moreover, there are few studies on wave energy assessment in the Southern Indian Ocean. Hammar et al. [14] used the altimetry dataset to investigate the wave energy potential in the Western Indian Ocean. They showed that the areas with higher potential are southeast Africa, south and east of Madagascar, and Reunion and Mauritius. Lavidas and Venugopal [15] used 18-years of the simulated wave using SWAN to estimate the wave energy potential and its variability in South Africa and represented promising conditions for offshore wave applications regarding the low easily accessible depths and short coast distances. Kamranzad and Mori [1] assessed the impact of climate change on the sustainability of wave energy in southeast Africa and indicated higher values and stability in Reunion, Mauritius, and southern Madagascar.

Besides, as well as the available resources, the sustainability of wave energy is required to be taken into consideration [16]. Considering the impact of climate change, the supply of energy needs to be as stable as possible and the suitable location for extraction of energy must be selected based on that for sustainable future development. However, none of the above-mentioned studies have considered the impact of climate change and the sustainability of the resources in the long term in defining suitable locations using the updated set of climate data, i.e., CMIP5 [17].

Therefore, in this study, the impact of climate change on the available wave energy in the Western Indian Ocean as a supply of energy for its surrounding coasts will be discussed, in order to introduce the most suitable areas for providing part of the energy demand. For this purpose, two 25-yearly periods of historical and future projections of wave climate using a high-resolution CMIP5 global climate model will be utilized and the sustainability of the resources will be evaluated in various regions. In addition, the intra-annual variation of wave energy will be assessed to consider both short-term variation and long-term change. Finally, the total and exploitable storages of the potential 
of wave energy will be evaluated, and their change due to climate change will be discussed. Various criteria will be assessed to define the stability of wave energy in both short and long-term. Section 2 describes the dataset and method and Section 3 discusses the spatio-temporal assessment in various time scales using different criteria. Finally, Section 4 provides a summary of the different criteria discussed in the previous sections.

\section{Materials and Methods}

\subsection{Study Area and Data Resources}

The Indian Ocean, where a large number of the Earth's population is living in surrounding lands, contains about 20\% of the surface of the Earth's ocean (Figure 1). The Indian Ocean experiences monsoon winds in the northern parts from October to January (northeast monsoon) and from June to September (southwest monsoon) [18]. In southern parts, the Indian Ocean also encounters the monsoons from January to March (northeast monsoon) and July to September (southwest monsoon) [19]. The wave climate assessment in the Indian Ocean shows that it is strongly affected by the swells from the Southern Ocean [20], while the Northern Indian Ocean is affected highly by the swells traveling from the Southern Indian Ocean towards the north especially in calm seasons [18].

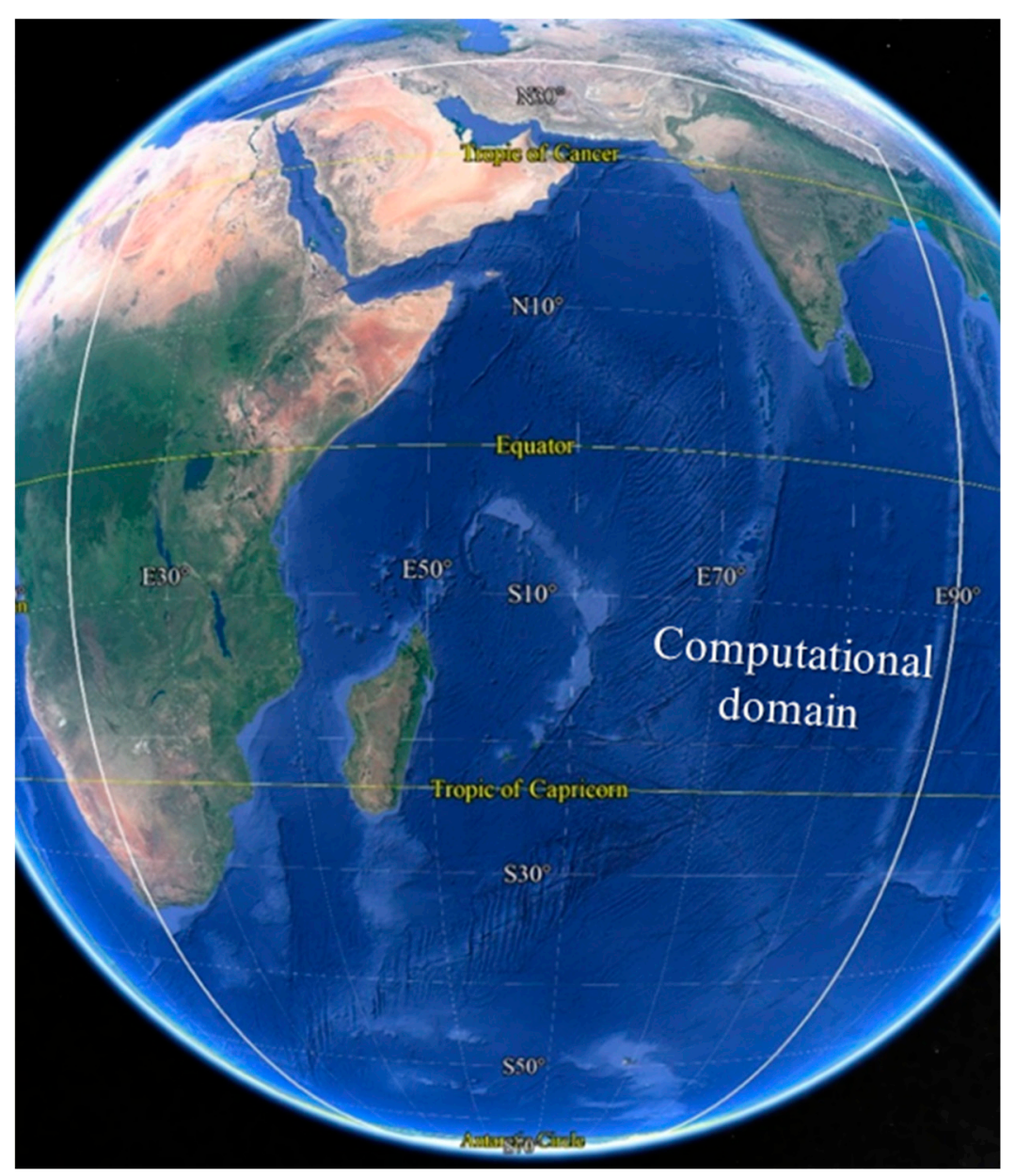

Figure 1. Study area and computational domain.

Considering the noticeable Intra-annual variation in the wind and wave climate in the Indian Ocean, it is important to define the suitable potential areas for wave energy extraction based on their sustainability. However, as well as short-term variations, long-term changes should also be taken into account. For this purpose, Kamranzad and Mori [1] proposed a Climate Stability Index (CSI) that 
comprises Monthly Variability Index (MVI) in both historical and future projections and the relative change of the intended parameter in the future. Lower change in both short and long-term conveys higher stability of the parameter.

In this study, the long-term wave simulation using a high-resolution global climate model (MRI-AGCM3.2S) [21] provided by the Japan Meteorological Research Institute (MRI) was used to calculate the wave power values in the study area. The utilized model was SWAN (Simulating Waves Nearshore) [22] with the computational domain covering the area between $20^{\circ} \mathrm{E}-90^{\circ} \mathrm{E}$ in longitude and $71^{\circ} \mathrm{S}-30^{\circ} \mathrm{N}$ in latitude with the spatial resolution of $0.5^{\circ}$. The frequency domain consisted of the range from 0.03 to $1 \mathrm{~Hz}$ with 36 bins on a logarithmic scale, and the directional computational grid was divided into 36 bins of 10 degrees.

The simulations were done for a historical (1979-2003) and future (2075-2099) periods. For the future projections, RCP (Representative Concentration Pathway) 8.5 of the CMIP5 was used [23,24] as only this scenario was available with super-high-resolution. In fact, considering only one scenario is not enough to reduce the uncertainties in future projection. However, using a high-resolution dataset is vital in order to generate the high-resolution wave dataset assisting the reducing the uncertainties in numerical modeling. The model has been calibrated against the gridded Satellite multi-mission wave products from Aviso (http://www.aviso.oceanobs.com/) and the results have shown that the model is reliable to produce the wave characteristics in the Western Indian Ocean. A detailed discussion on the wave modeling and the validation procedure, qualitatively and quantitatively, can be found in [1].

\subsection{Wave Energy Calculation}

The simplified deep water equation for calculating the wave power parameter was utilized. In order to reach that equation, the wave energy density is calculated by [25]:

$$
\mathrm{E}=1 / 16 \rho g \mathrm{H}_{\mathrm{s}}^{2}
$$

in which, $\rho, g$ and $H_{s}$ are density of water, gravitational acceleration and significant wave height, respectively. The wave power $(\mathrm{P})$ is calculated as:

$$
\mathrm{P}=\mathrm{EC}_{\mathrm{g}}=\mathrm{ECn}
$$

where $C_{g}, C$ and $n$ show the wave group speed, wave speed and the ratio of wave group speed to the wave speed, respectively. $C$ is the ratio of wavelength $\left(\mathrm{gT}^{2} / 2 \pi\right.$ for deep water) to wave period $(\mathrm{T})$ and $\mathrm{n}$ is considered approximately equal to 0.5 for deep water condition. Hence, the Equation (2) can be re-written as:

$$
\mathrm{P} \approx 0.49 \mathrm{H}_{\mathrm{S}}^{2} \mathrm{~T}
$$

Considering that the real sea state includes a large number of regular waves, a variance spectral density function should be used to describe a mixture of different amplitudes, frequencies and directions. Therefore, the wave power per unit width of waves in deep water is calculated based on the energy period $\left(\mathrm{T}_{\mathrm{e}}\right)[26]$ :

$$
\mathrm{P} \approx 0.49 \mathrm{H}_{\mathrm{s}}^{2} \mathrm{~T}_{\mathrm{e}}
$$

while $T_{e}$ is equal to the parameter $T_{m-10}$ in SWAN and is calculated from $m_{-1} / m_{0}$, where $m_{n}$ is the $\mathrm{n}$-th moment of the energy density spectrum $(\mathrm{E}(\mathrm{f})$ ) in which $\mathrm{f}$ is the frequency (SWAN scientific and technical documentation, 2019):

$$
m_{n}=\int_{0}^{\infty} f^{n} E(f) d f
$$

After calculating the wave power based on wave characteristics, the stability of the resources in the short-term can be evaluated using the Monthly Variability Index (MVI) which is calculated based on the ratio of the difference between the highest and lowest mean monthly wave power to the mean annual wave power. 
In order to consider the long-term change, the Climate Stability Index (CSI) is used. CSI is calculated using Equation (6) [1]:

$$
\mathrm{CSI}_{\mathrm{p}}=\frac{\mathrm{P}_{\mathrm{H}}}{\left|\left(\mathrm{MVI}_{\mathrm{F}}-\mathrm{MVI}_{\mathrm{H}}\right) \times \mathrm{MVI}_{\mathrm{H}} \times\left(\mathrm{P}_{\mathrm{F}}-\mathrm{P}_{\mathrm{H}}\right)\right|}
$$

in which, $\mathrm{P}$ is the mean annual wave power with $\mathrm{H}$ and $\mathrm{F}$ stand for historical and future periods, respectively. This index contains both short-term variation (MVI) and long-term change (Relative change: $\left.\left(\mathrm{P}_{\mathrm{F}}-\mathrm{P}_{\mathrm{H}}\right) / \mathrm{P}_{\mathrm{H}}\right)$.

\section{Results and Discussion}

After validation of the model, it was performed for two 25-yearly periods (historical (1979-2003) and future (2075-2099) projections) and the time series of wave power was obtained based on significant wave height and wave period generated directly by SWAN in each output grid point. The spatio-temporal assessment of wave power in the study area was performed in order to firstly, evaluate the intra-annual (seasonal and mean annual) variation of the wave power and its relationship with natural fluctuations due to monsoon, etc., and secondly, to investigate the impact of climate change and the possible future change of the available resources.

\subsection{Annual and Seasonal Mean Values and Changes}

The seasons were considered as three monthly spans: December-January-February (DJF), March-April-May (MAM), June-July-August (JJA) and September-October-November (SON). Figure 2 shows the annual and seasonal mean values of wave power in the Western Indian Ocean. According to this figure, the mean annual wave power in the Southern Indian Ocean reaches around $120 \mathrm{~kW} / \mathrm{m}$ at the highest, while during JJA and SON, the maximum mean wave power can even reach $150 \mathrm{~kW} / \mathrm{m}$. The Northern Indian Ocean contains a lower amount of wave energy especially in semi-enclosed basins, i.e., the Persian Gulf and the Red Sea. The areas under sheltering effect such as west of Madagascar and northeast of Sri Lanka also experience lower amounts of energy. The area with the highest values of wave power in the Northern Indian Ocean is the Horn of Africa and Oman continental shelf, especially during JJA (southwest monsoon), while the calmest seasons in the Northern Indian Ocean are DJF and MAM.

The future change in annual and seasonal mean wave power has been indicated in Figure 2 by both absolute and relative changes. On an annual scale, a slight decrease occurs in the Northern Indian Ocean, with the highest reduction during JJA (approximately $10 \mathrm{~kW} / \mathrm{m}$ ) in the Arabian Sea, whereas the Southern Indian Ocean experiences an increase in wave power up to $15 \mathrm{~kW} / \mathrm{m}$ in the eastern boundaries. There is a reduction in wave power in the area between $30^{\circ} \mathrm{S}$ and $40^{\circ} \mathrm{S}$, which is the consequence of shifting the westerly winds towards the south [1]. This particularly happens during DJF (nearly northeast monsoon), while the largest future increase in the wave power in the Southern Indian Ocean occurs during SON. In terms of relative change, areas with the highest values are the areas with the lowest mean wave power. For instance, the mean wave power in the Northern Indian Ocean is relatively low during SON, but a slight increase of around $5 \mathrm{~kW} / \mathrm{m}$ has caused a relative change of about $40 \%$ in some regions. 


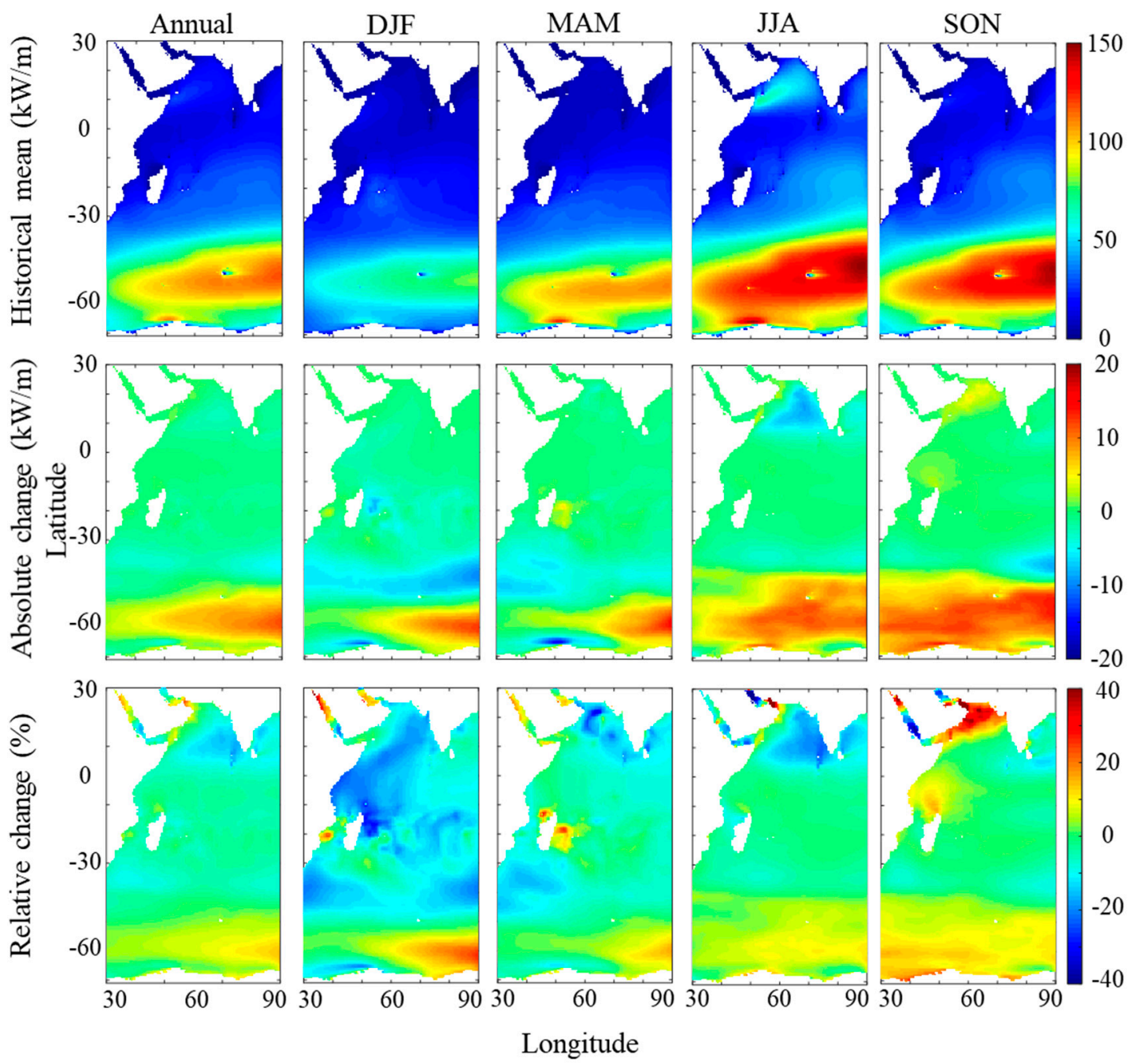

Figure 2. Mean annual and seasonal wave power in historical period, and its absolute and relative change in the future.

Figure 3 shows the nearshore spatio-temporal distribution of mean seasonal wave power, in the historical period and its absolute and relative change in the future. The area south of $30^{\circ} \mathrm{S}$ was excluded in order to focus on more inhabited areas. As this figure shows, the wave power reaches the highest values in JJA in the Northern Indian Ocean, almost the same highest value as in the Southern Indian Ocean. The nearshore areas of the Southern Indian Ocean, especially east of Madagascar, Reunion and Mauritius experience high values of wave power almost all year round. The largest decrease in future wave power in the Northern Indian Ocean takes place in western coasts of India, Maldives, and south to the west of Sri Lanka, during JJA, while the largest increase in wave power in the Northern Indian Ocean occurs in Oman continental shelf during SON. The nearshore areas of SIO seem more stable in terms of long-term changes in the future, except for east and northeast of Madagascar where the largest decrease in wave power happens during DJF (about 30\%). 

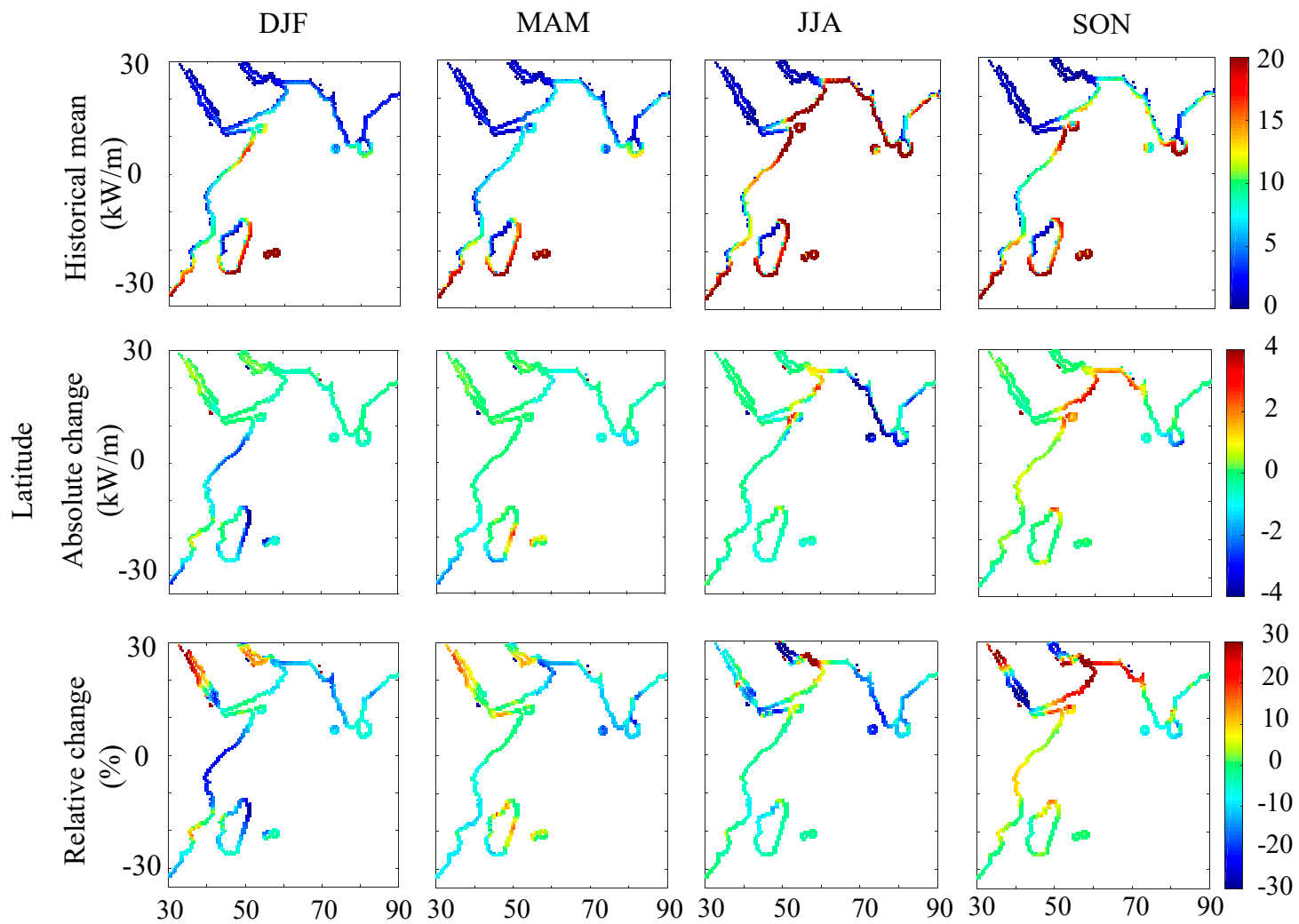

Longitude

Figure 3. Mean seasonal nearshore wave power in historical period, and its absolute and relative change in the future.

\subsection{Stability of Wave Energy Resources in Nearshore Areas}

In order to investigate the stability of the resources in the short-term, MVI was obtained for the nearshore wave power in the Western Indian Ocean. Figure 4 represents the MVI values for both historical and future projections. According to this figure, the spatial distribution of MVI is nearly similar for historical and future periods, except for the western parts of the Gulf of Oman near the Strait of Hormuz, which will increase, and west of India which will decrease slightly in the future. Figure 4 also shows that the monthly variability is lower in the Southern Indian Ocean compared to the Northern Indian Ocean.

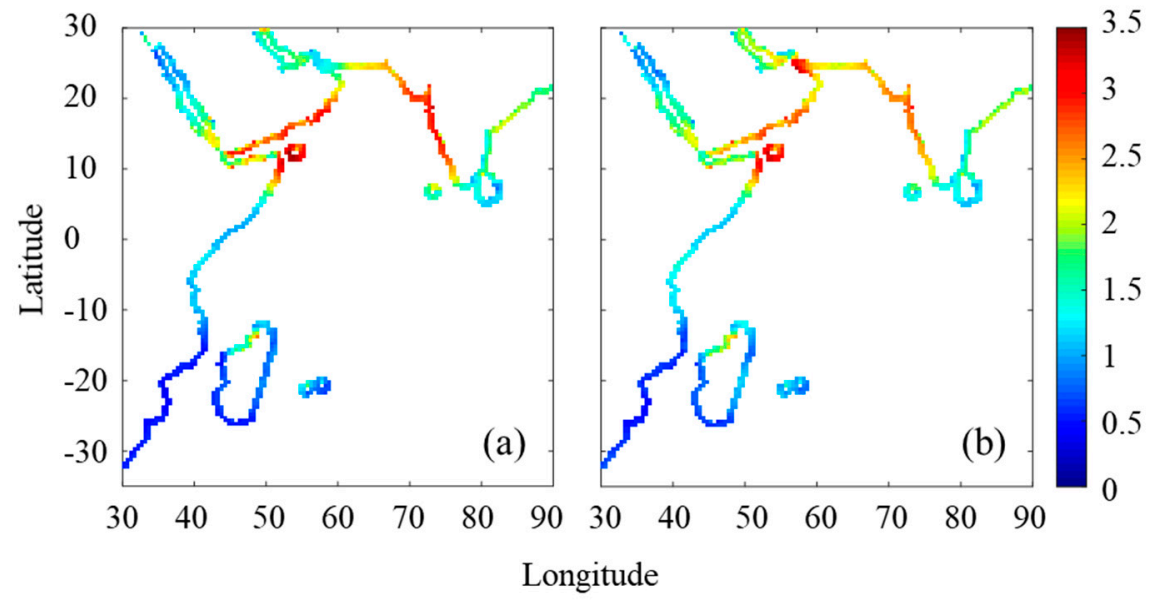

Figure 4. MVI (a) historical (b) future. 
In order to detect the areas with the highest values of wave power and the lowest variability in the monthly scale, the ratio of mean wave power to MVI was calculated and shown in Figure 5. According to this figure, the spatial distribution remains the same in the future indicating a higher potential and higher stability in the Southern Indian Ocean, especially southeast Africa, south of Madagascar and south of Reunion and Mauritius. In the Northern Indian Ocean, values in the south of Sri Lanka implement higher potential and stability.

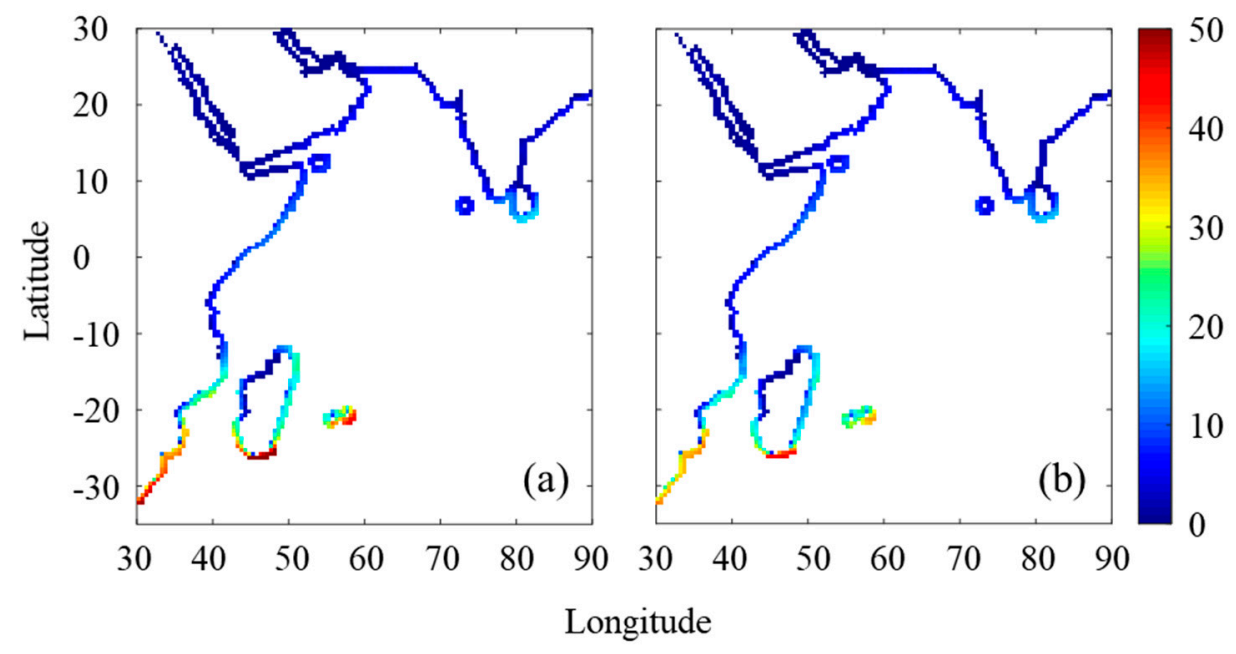

Figure 5. Ratio of mean wave power to MVI (a) historical (b) future.

As discussed before, for defining an area as a suitable location for wave energy extraction, as well as the amount of power, the stability of the resources is important to assess. The stability in terms of short-term variation (monthly) has been discussed in Figures 4 and 5, whereas the long-term change due to climate change has been taken into account using CSI. Figure 6 shows the CSI value for wave power parameter in nearshore areas of the Western Indian Ocean implying the regions with the highest stability in terms of both short-term variation and long-term change. According to this figure, the northern coasts of the Gulf of Oman, Horn and Africa and parts of Sri Lanka experience the lowest variability and change in the Northern Indian Ocean. In the Southern Indian Ocean, the areas with the most stable supply of wave power are southeast Africa, south of Madagascar and east of Reunion and Mauritius islands.

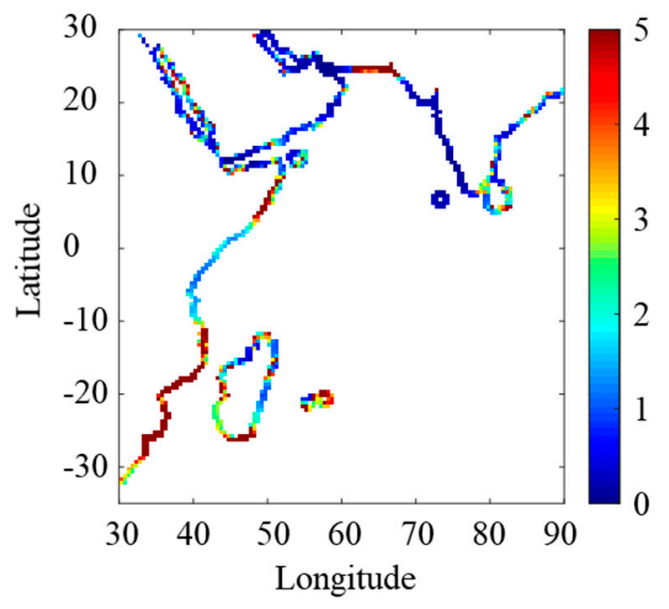

Figure 6. CSI for nearshore wave power. 


\subsection{Total and Exploitable Storage of Wave Energy}

In order to investigate the possibility of utilizing the wave energy converters, the total and exploitable storages of wave energy per unit area $\left(E_{t}\right.$ and $E_{e}$, respectively) were also obtained. $E_{t}$ is calculated by multiplying mean wave power $\left(\mathrm{P}_{\text {mean }}\right)$ and the total hours all year round $(t=8760$ h), while $E_{e}$ is calculated based on $P_{\text {mean }}$ and the theoretical exploitable time, i.e., the total hours corresponding to wave power higher than $2 \mathrm{~kW} / \mathrm{m}$ [27]. Figure 7 indicates the exploitable storage of energy and its relative change in the future as well as the ratio of exploitable to total storages of energy in the historical period in addition to their change in the future.
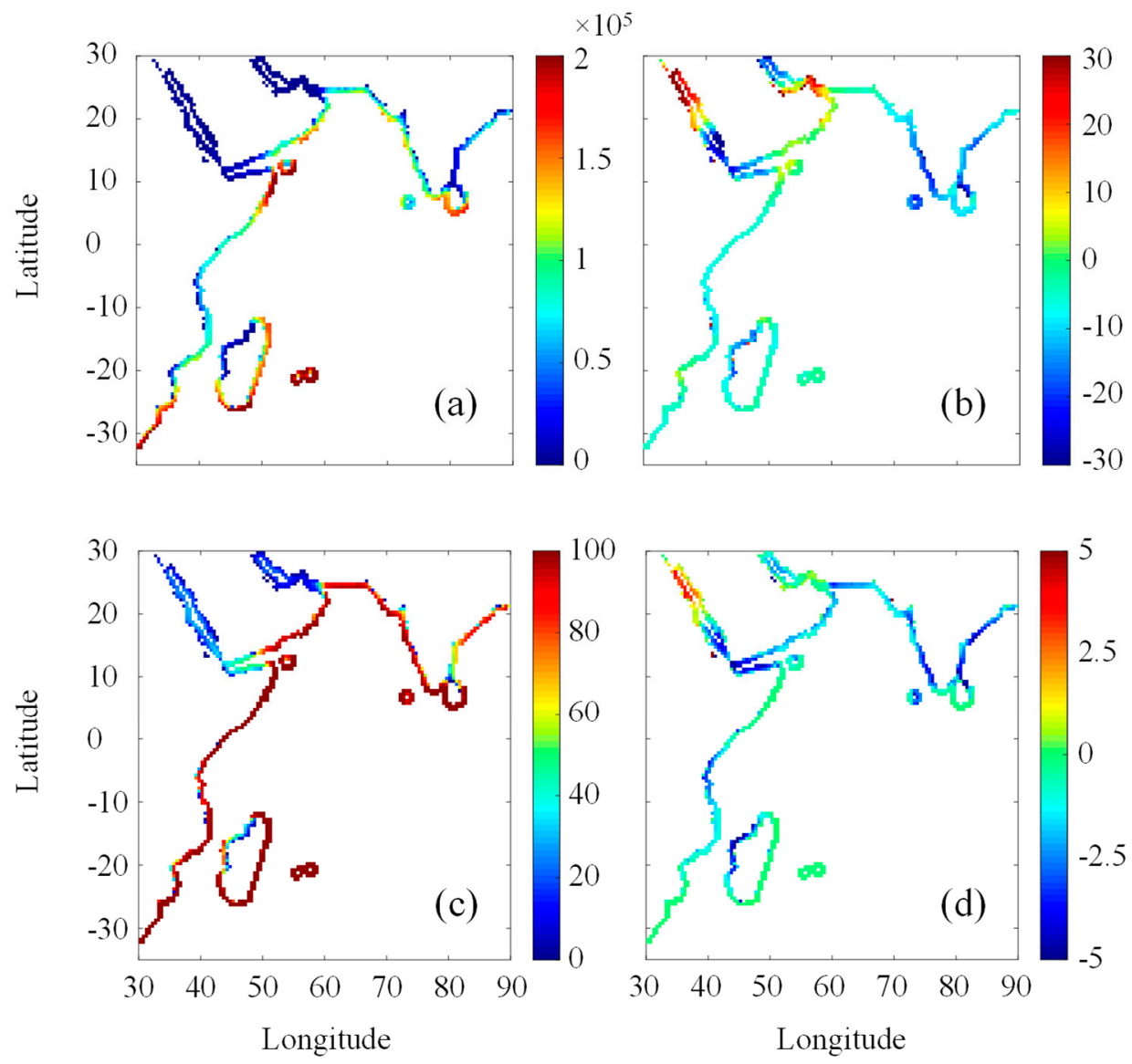

Figure 7. (a) Historical $E_{e}$, (b) Relative change of $E_{e}$, (c) historical ratio of $E_{e} / E_{t}$ and (d) Absolute change of Ratio of $E_{e} / E_{t}$.

According to Figure 7a, the spatial distribution of $\mathrm{E}_{\mathrm{e}}$ illustrates the higher potential in certain areas in the Northern and Southern Indian Ocean. In the Northern Indian Ocean, the highest values exist in the Horn of Africa and Socotra Island, as well as part of Oman continental shelf and south and west of Sri Lanka. In the Southern Indian Ocean, the highest values of $\mathrm{E}_{\mathrm{e}}$ can be found in southeast Africa, south and east of Madagascar and Reunion and Mauritius islands. Regarding the relative change (Figure $7 \mathrm{~b}$ ), the areas with the highest values will experience the lowest change in the future while the most intensive changes will occur in semi-enclosed seas (i.e., the Persian Gulf and the Red Sea). Moreover, there will be a reduction of about $20 \%$ in the western Indian continental shelf and Maldives. Figure $7 \mathrm{c}$ indicates that almost in all the nearshore areas of Southern Indian Ocean the ratio of $E_{e}$ to $E_{t}$ has been $100 \%$, which means the wave power exceeds $2 \mathrm{~kW} / \mathrm{m}$ the whole year round. The areas with lower values of this ratio are semi-enclosed seas, east of India and northwest of Madagascar. In the future, this ratio remains the same in most areas in the Southern Indian Ocean, while most of the nearshore areas of the Northern Indian Ocean will experience the reduction of this ratio (Figure 7d). 


\section{Summary and Conclusions}

Wave power was assessed spatio-temporally in the Western Indian Ocean for both historical and future projections based on the wave simulation using the MRI-AGCM3.2S model. The analysis was performed based on intra-annual variation (monthly, seasonal and annual) and long-term changes (absolute and relative changes). The spatio-temporal distribution of the wave power showed that the maximum mean wave power in the domain reaches around $150 \mathrm{~kW} / \mathrm{m}$ in the Southern Indian Ocean during JJA and SON. The Northern Indian Ocean and its marginal seas contain lower values of wave power comparing to the Southern parts. Although, wave power reaches the peak in the Horn of Africa and Oman continental shelf especially during the southwest monsoon (JJA). The Northern Indian Ocean becomes relatively calm during DJF and MAM. Regarding future change, the Southern Indian Ocean will be subject to a considerable increase of wave power up to $15 \mathrm{~kW} / \mathrm{m}$ according to the future projection, while the Northern Indian Ocean will experience a slight decrease.

Considering that wave energy extraction is carried out in the areas adjacent to the land, the analysis was continued for the nearshore areas. The results showed that although generally, the wave power is considerably higher in the Southern Indian Ocean, the nearshore areas of the Northern Indian Ocean are exposed to nearly similar wave power, as well. This indicates a highly interesting potential for wave energy exploitation. The largest future change in wave power will occur in western coasts of India, Maldives, and south to the west of Sri Lanka, as a reduction during JJA. The largest increase in wave power in the Northern Indian Ocean occurs in Oman continental shelf during SON. The Southern Indian Ocean shows a more stable wave power climate in terms of future changes.

The results also represent that the Southern Indian Ocean contains lower monthly variability comparing to the Northern Indian Ocean. Moreover, monthly variability will not change, except for the western parts of the Gulf of Oman near the Strait of Hormuz with higher and west of India with lower variability in the future. The ratio of mean wave power to the monthly variability index also illustrates a higher potential and stability in the Southern Indian Ocean. Furthermore, assessment of long-term changes in the available wave power using climate stability index showed that the northern coasts of Gulf of Oman, Horn of Africa and parts of Sri Lanka in the Northern Indian Ocean and southeast Africa, south of Madagascar and east of Reunion and Mauritius islands in the Southern Indian Ocean are the areas with the least change in the wave power in both short and long-term.

As well as the wave power, the total and exploitable storages of the wave energy and their change according to the future projection were assessed and the results indicated that in the Southern Indian Ocean, the exploitable storage is almost equal to the total storage of wave energy except for northwest of Madagascar. In the Northern Indian Ocean, the lowest ratio of exploitable to total storage of wave energy can be found in the marginal seas (which experience the most intensive changes in the future, as well) and east of India. In addition, the nearshore areas of the Northern Indian Ocean will experience the reduction of the ratio of exploitable to total storage of wave energy in the future.

As a summary to the above-mentioned investigations and considering the different criteria such as the amount of wave power, the ratio of wave power to monthly variability, climate stability, exploitable storage of energy and its stability, it can be concluded that south of Sri Lanka, Horn of Africa, southeast Africa, south of Madagascar and Reunion and Mauritius islands are the most suitable areas for extraction of wave energy. Further assessment is required on a regional scale using wave downscaling in order to provide the dataset with higher accuracy in suitable areas and discuss the most appropriate locations for being considered as the potential spots for the wave energy harvesting.

Author Contributions: Conceptualization, B.K., G.L. and K.T.; Methodology, B.K., G.L. and K.T.; Software, B.K. and G.L.; Validation, B.K.; Formal analysis, B.K. and G.L.; Investigation, B.K. and G.L.; Resources, B.K.; Data curation, B.K. and G.L.; Writing-original draft preparation, B.K.; Writing-review and editing, B.K., G.L. and K.T.; Visualization, B.K.; Supervision, B.K.; Project administration, B.K.; Funding acquisition, B.K. and G.L. All authors have read and agreed to the published version of the manuscript.

Funding: The first author (B.K.) has been supported by the Hakubi Center for Advanced Research at Kyoto University and JSPS Grants-in-Aid for Scientific Research (KAKENHI) supported by the Ministry of Education, 
Culture, Sports, Science, and Technology-Japan (MEXT). The second author (G.L.) has received funding from the European Union's Horizon 2020 research and innovation programme under the Marie Skłodowska-Curie grant agreement No 787344 .

Acknowledgments: The authors are thankful to Disaster Prevention Research Institute, Kyoto University for sharing the wind dataset.

Conflicts of Interest: The authors declare no conflict of interest. The funders had no role in the design of the study; in the collection, analyses, or interpretation of data; in the writing of the manuscript, or in the decision to publish the results.

\section{References}

1. Kamranzad, B.; Mori, N. Future wind and wave climate projections in the Indian Ocean based on a super-high-resolution MRI-AGCM3.2S model projection. Clim. Dyn. 2019, 53, 2391-2410. [CrossRef]

2. Sasaki, W. Predictability of global offshore wind and wave power. Int. J. Mar. Energy 2017, 17, 98-109. [CrossRef]

3. Sannasiraj, S.A.; Sundar, V. Assessment of wave energy potential and its harvesting approach along the Indian coast. Renew. Energy 2016, 99, 398-409. [CrossRef]

4. Aboobacker, V.M. Wave energy resource assessment for eastern Bay of Bengal and Malacca Strait. Renew. Energy 2017, 114, 72-84. [CrossRef]

5. Etemad-Shahidi, A.; Kamranzad, B.; Chegini, V. Wave energy estimation in the Persian Gulf. In Proceedings of the International Conference on Environmental Pollution and Remediation, Ottawa, ON, Canada, 17-19 August 2011.

6. Mazaheri, S.; Kamranzad, B.; Hajivalie, F. Modification of 32 years ECMWF wind field using QuikSCAT data for wave hindcasting in Iranian Seas. J. Coast. Res. 2013, 344-349. [CrossRef]

7. Kamranzad, B.; Etemad-Shahidi, A.; Chegini, V. Assessment of wave energy variation in the Persian Gulf. Ocean Eng. 2013, 70, 72-80. [CrossRef]

8. Kamranzad, B.; Etemad-Shahidi, A.; Chegini, V.; Yeganeh-Bakhtiary, A. Climate change impact on wave energy in the Persian Gulf. Ocean Dyn. 2015, 65, 777-794. [CrossRef]

9. Kamranzad, B.; Etemad-Shahidi, A.; Chegini, V. Developing an optimum hotspot identifier for wave energy extracting in the northern Persian Gulf. Renew. Energy 2017, 114, 59-71. [CrossRef]

10. Kamranzad, B. Persian Gulf zone classification based on the wind and wave climate variability. Ocean Eng. 2018, 169, 604-635. [CrossRef]

11. Mahmoodi, K.; Ghassemi, H.; Razminia, A. Temporal and spatial characteristics of wave energy in the Persian Gulf based on the ERA5 reanalysis dataset. Energy 2019, 187, 115-991. [CrossRef]

12. Langodan, S.; Viswanadhapalli, Y.; Dasari, H.P.; Knio, O.; Hoteit, I. A high-resolution assessment of wind and wave energy potentials in the Red Sea. Appl. Energy 2016, 181, 244-255. [CrossRef]

13. Aboobacker, V.M.; Shanas, P.R.; Alsaafani, M.A.; Albarakati, A.M.A. Wave energy resource assessment for Red Sea. Renew. Energy 2017, 114, 46-58. [CrossRef]

14. Hammar, L.; Ehnberg, J.; Mavume, A.; Cuamba, B.C.; Molander, S. Renewable ocean energy in the Western Indian Ocean. Renew. Sustain. Energy Rev. 2012, 16, 4938-4950. [CrossRef]

15. Lavidas, G.; Venugopal, V. Prospects and applicability of wave energy for South Africa. Int. J. Sustain. Energy 2018, 37, 230-248. [CrossRef]

16. Kamranzad, B.; Etemad-Shahidi, A.; Chegini, V. Sustainability of wave energy resources in southern Caspian Sea. Energy 2016, 97, 549-559. [CrossRef]

17. Taylor, K.E.; Stouffer, R.J.; Meehl, G.A. An Overview of CMIP5 and the experiment design. Bull. Am. Meteorol. Soc. 2012, 93, 485-498. [CrossRef]

18. Seemanth, M.; Bhowmick, S.A.; Kumar, R.; Sharma, R. Sensitivity analysis of dissipation parameterizations in a third-generation spectral wave model, WAVEWATCH III for Indian Ocean. Ocean Eng. 2016, 124, 252-273. [CrossRef]

19. Aguiar-González, B.; Ponsoni, L.; Ridderinkhof, H.; van Aken, H.M.; de Ruijter, W.P.M.; Maas, L.R.M. Seasonal variation of the South Indian tropical gyre. Deep Sea Res. Part I Oceanogr. Res. Pap. 2016, 110, 123-140. [CrossRef]

20. Young, I.R. Seasonal variability of the global ocean wind and wave climate. Int. J. Climatol. 1999, 19, 931-950. [CrossRef] 
21. Mizuta, R.; Yoshimura, H.; Murakami, H.; Matsueda, M.; Endo, H.; Ose, T.; Kamiguchi, K.; Hosaka, M.; Sugi, M.; Yukimoto, S.; et al. Climate Simulations Using MRI-AGCM3.2 with $20 \mathrm{~km}$ Grid. J. Meteorol. Soc. Jpn. Ser. II 2012, 90A, 233-258. [CrossRef]

22. Booij, N.; Ris, R.C.; Holthuijsen, L.H. A third-generation wave model for coastal regions: 1 . Model description and validation. J. Geophys. Res. Ocean. 1999, 104, 7649-7666. [CrossRef]

23. Hibbard, K.A.; Meehl, G.A.; Cox, P.M.; Friedlingstein, P. A strategy for climate change stabilization experiments. Eos Trans. Am. Geophys. Union 2007, 88, 217-221. [CrossRef]

24. Moss, R.H.; Edmonds, J.A.; Hibbard, K.A.; Manning, M.R.; Rose, S.K.; van Vuuren, D.P.; Carter, T.R.; Emori, S.; Kainuma, M.; Kram, T.; et al. The next generation of scenarios for climate change research and assessment. Nature 2010, 463, 747-756. [CrossRef] [PubMed]

25. Hughes, M.G.; Heap, A.D. National-scale wave energy resource assessment for Australia. Renew. Energy 2010, 35, 1783-1791. [CrossRef]

26. Abbaspour, M.; Rahimi, R. Iran atlas of offshore renewable energies. Renew. Energy 2011, 36, 388-398. [CrossRef]

27. Zhou, G.; Huang, J.; Yue, T.; Luo, Q.; Zhang, G. Temporal-spatial distribution of wave energy: A case study of Beibu Gulf, China. Renew. Energy 2015, 74, 344-356. [CrossRef]

(C) 2020 by the authors. Licensee MDPI, Basel, Switzerland. This article is an open access article distributed under the terms and conditions of the Creative Commons Attribution (CC BY) license (http://creativecommons.org/licenses/by/4.0/). 